\title{
Phrasal verbs and analogical generalization in Late Modern Spoken English
}

\author{
Ljubica Leone, University of Salerno, Italy
}

\begin{abstract}
This present study focuses on the description of the development of phrasal verbs (PVs) in Late Modern Spoken English and, specifically, aims at analysing texts taken from the Proceedings of the Old Bailey, a valuable source of spoken language from past time periods. From a diachronic perspective, the emergence of new PVs can be considered strictly linked to the process of direct formation and analogical generalization resulting in PVS as they are known in Present Day English (PDE). This study is a corpus-based investigation conducted on the Late Modern English-Old Bailey Corpus (LModE-OBC), a corpus that has been compiled by using texts from the Proceedings of the Old Bailey and annotated with the Visual Interactive Syntax Learning interface (VISL). The analysis reveals that, in the time span 1750-1850, this verbal group underwent a gradual process of change also due to the contribution of direct formation and analogical generalization, a process that started in the Early Modern English (EME) period and that continued to the Late Modern English (LModE) era.
\end{abstract}

\section{Introduction}

The aim of this research is to analyse the development of phrasal verbs (PVs) in the Late Modern English (LModE) period and, specifically, to investigate the changes which occurred in spoken language making use of the Proceedings of the Old Bailey, a source of transcripts from past time that is still unexplored. In particular, this study investigates how the process of direct formation through analogical generalization affected PVs in the years 1750-1850.

To clearly understand how specific linguistic items emerge over time, it is necessary to investigate the mechanisms that can potentially promote variation in use and that, diachronically, can give rise to new combinations. In the case of PVs, their development and specifically the discussion of the processes that were involved in their establishment, represent an important topic still now 
under debate. The problem is that PVs "may be variously considered from the perspective of grammaticalization, lexicalization and idiomatization" (Brinton and Akimoto 1999: 11-12). In fact, when studying these processes, there is a kind of confusion, and, in addition to these questions, other problematic issues arise, mainly concerning the description of the "factors" (Fisher 2007: 30-43) and the internal steps that gradually lead to syntactic ossification and to conventionalization ${ }^{1}$ on the syntagmatic and paradigmatic levels.

In fact, since the early stages in the history of the English language, the emergence of PVs is connected with the two-stage process of particle shifting (Denison 1981: 114) that first caused the movement of the adverbial particle to a post-verbal position only in finite verbs, and that then provoked, per analogy, the same shift in the particle position also in non-finite verbs (Denison 1981: 118; Claridge 2000: 85; Brinton and Traugott 2005: 124). From this perspective, the process of direct formation and analogy was also at work in the following periods of the development of English, operating as a catalyst for the establishment of the linguistic structures towards the emergence of new combinations and innovative patterns of use. Overall, this is a construction that appeared to be very popular in the 19th and 20th centuries (Claridge 2000; Rodríguez-Puente 2012; Thim 2012) and, in addition, a linguistic element that was greatly involved in innovation and change. It is said (Denison 1998: 222-224; Claridge 2000: 114-116; Rodríguez-Puente 2012: 77-88) that, during the LModE era, this verbal group was affected by systematic processes of internal restructuring and paradigmatic variation that gave rise to new forms but, at the same time, it should be noted that these processes also caused a decline in use and complete loss of other patterns.

From a linguistic perspective, it is of great importance to outline the ongoing process of change and reconstruct the reasons that lay behind it. In particular, my intention is to study the link between different structures, trying to explain how direct formation and analogy promoted the emergence of new PVs during the LModE period. In order to describe the processes involved in the rise of new PVs, the Late Modern Spoken English-Old Bailey corpus (LModE-OBC) has been collected and then automatically parsed by using the VISL (Visual Interactive Syntax Learning) interface and its tools. The corpus is a collection of texts (court records) from the Proceedings of the Old Bailey (http://www.oldbaileyonline.org), covering a period of 100 years, from 1750 to 1850 . According to the classification proposed by Culpeper and Kytö (2010: Ch.1), the texts contained in the corpus belong to the speech-related genre, namely to the speech-based group. In fact, they "are based on an actual 'real-life' speech event" (Culpeper and Kytö 2010: 17) and, thus, they can give us some insights into what the spo- 
ken language was like. In addition, they can provide relevant information on the changes that occurred within the spoken dimension, which has been rather neglected so far, due to the lack of materials predating the audio recording technology.

The paper is organized as follows. Section 2 provides a description of the processes affecting PVs in general, Section 3 describes the current study providing details about method and materials, while Section 4 contains the description of the results and considerations strictly related to the data.

\section{Theoretical background}

Many studies have outlined that the emergence of PVs is strictly linked to the analytic tendency of the English language in its historical development (Bolinger 1971; Fraser 1974; Hiltunen 1999). Their origin is in fact associated with both "the structural shift from prefixes to post-verbal particles" (Brinton 1988: 189), dating back to the Old English period and the "evolution of verbal periphrases" (Brinton 1988: 96) through "purely language-internal" changes (Claridge 2000: 87). However, even if there is evidence for such a complex process of change, what still remains under debate is the explanation of the mechanisms that caused the emergence of PVs and the motivations that got them gradually conventionalized in language use.

As widely emphasised in historical studies (Brinton and Akimoto 1999; Hopper and Traugott 2003 [1993]; Brinton and Traugott 2005; RodríguezPuente 2012), the emergence and the loss of specific PVs originated in the grammaticalization or lexicalization of the particles and in the existence of competing alternative structural analyses (Brinton and Traugott 2005: 122-125). More specifically, in the establishment of new PVs, among the mechanisms that were at work in the LModE period, there are the process of direct formation, consisting of both zero-derived verbs and analogical processes, and the syntactic reanalysis consequent on the decategorialization of the non-verbal element. In fact, the progression of a linguistic item over time is influenced by both internal and external factors, and among them analogy and reanalysis are recognized as the most significant mechanisms in language change (Hopper and Traugott 2003 [1993]: 39), and the mechanisms which also operated during the LModE period, despite not being as operative as in the previous stages. In fact, it is well known that the emergence of PVs such as to pass on, to look down, to run down, to walk up, to do up and to pay down can be seen as being strictly connected with these processes and with the restructuring of the whole sentence. In this regard, the decategorialization of the non-verbal element determined a shift from a preposi- 
tional to a particle status with the consequent lexicalization of the whole $\mathrm{V}+$ particle construction. In fact, the non-verbal element of PVs is first considered as a kind of adverb or preposition that then acquired a particle status (Brinton 1988).

Moreover, it is undeniable that also external factors such as the Scandinavian influence (Thim 2012: 185) may have played a role in their establishment together with the Old Norse phrasal constructions that acted as a sort of "catalyst, stimulating the further development of the postverbal construction type already present in OE" (Claridge 2000: 87). Specifically, the development of PVs is strictly linked to both the Latin and Scandinavian influence that gave rise to the use of new forms and that, especially in the case of Latin, contributed to the use of "verb-adverb collocations as translation-equivalents of Latin compounds, and secondly to a rather greater use of compounds" (Denison 1981: 156), a linguistic use of verbs which would have been unforeseeable without reference to the corresponding Romance items. However, it should be noted that also internal factors promoted the emergence of new combinations. In fact, in general, analogy "refers to the attraction of extant forms to already existing constructions" (Hopper and Traugott 2003 [1993]: 63-64) and, differently from reanalysis, operates along the paradigmatic axis and "on the two dimensions of similarity (paradigmatic) and indexicality (syntagmatic)" (Traugott 2011: 25). The fact is that "most changes involve extant (sub)systems, and what we most often see is an intertwining of reanalysis and analogy" (Traugott 2011: 24), the latter being either a "reduction of stem allomorphs" (from a morphological point of view) or "rule generalization/extension" (Traugott and Trousdale 2010:36). It is worth noting that, from this perspective, despite not being as evident as reanalysis, analogy also operates in the development of PVs, not only in the spread of innovative functions and structural constraints but also in the increasing opaqueness in meaning due to a metaphorical shift. In fact, it is possible to consider that meaning change is analogical in nature and that, diachronically, it interacts with "non-analogical metonymic, contextually derived changes" (Traugott 2011: 28). In the case of PVs, analogy occurred through the semanticpragmatic extension, syntactic and host-class expansion (Traugott and Trousdale 2010: 36) that allowed the new forms to spread to new contexts of use and to undergo institutionalization.

On these assumptions, direct formation as a process of language change was favoured by analogy, considered as both a "mechanism of spreading change" (Wanner 2006: 49) and a process of change itself "modelled from one set of expressions to another" (Campbell 2013 [1998]: 91; cf. also Traugott and Trousdale 2010: 35-39). This means that base verbs which possess similar meaning and also the connotative properties of the whole combination can be considered 
important elements that, potentially, can promote new linguistic items and that can resort to direct analogical formation. These processes promoted the rise of new lexical items but they also favoured the spread of innovative forms through rule generalization. More specifically, direct formation, rather than involving grammaticalization in a narrow sense, operates on linguistic items modifying the external surface and, in some cases, leaving unchanged the syntactic structure. This means that there would not be any kind of decategorialization or boundary creation and boundary shift (Traugott and Trousdale 2010: 33) because the formation of new lexical items can be seen as the result of "the attraction of extant forms to already existing constructions" (Brinton 1988: 64).

As regards PVs, it should be noted that, in the majority of cases, during the EME period the particle possesses a high degree in terms of productivity and a significant force on the paradigmatic level. This involves that the non-verbal element can combine with verbs of the same semantic field giving rise to new PVs that could also undergo further changes at the syntactic as well as at the semantic level. In addition, the freedom displayed by the particle to extend its context of use is also linked to the formation of zero-derived verbs involving nouns and adjectives (Denison 1981: 164) and to the emergence of antonymous pairs of particles as in the case of off/on, in/out and up/down.

On these bases, it is possible to hypothesise that the LModE period was characterised by tendencies that were similar to those of the previous era and, thus, that PVs developed through direct formation and spread via analogy to other contexts of use.

\section{The present study}

It is widely accepted that, during the LModE period, many PVs were mainly the result of syntactic reanalysis or the outcome of the changes affecting the previous periods (Kennedy 1920; Brinton and Akimoto 1999; Claridge 2000; Thim 2012) and that, during this era, they were well established. However, as stated in Section 2, despite the change not being as significant as in the previous stages, they continued to evolve and to present variation in use.

On these bases, the question that arises is whether and to what extent PVs were involved in the process of change during the LModE era, and what kind of effects this provoked on the whole linguistic system. More specifically, my intention is to point out how direct formation influenced the use of PVs in the time span 1750 - 1850 and to define the micro-steps characterising language change. My basic assumption is that PVs may be affected by a process of direct formation, and that this happens when a particle starts to collocate with other 
single lexical verbs conveying similar or antonymous meanings when compared to the extant forms. Considering that, with the exception of a few works (Denison 1981: Ch. 5), there is no specific reference to the description of the way direct formation and analogical generalization influenced the PVs during the LModE period, especially when the spoken dimension is taken into consideration, it is a compelling necessity to fill this gap in the literature and to elucidate how these processes operated in the years $1750-1850$. Specifically the aims are:

1. The identification of PVs resulting from direct formation and their spread through analogy;

2. The definition of direct formation in antonymous pairs of particles (i.e. off/ on, in/out, up/down);

3. The study of zero-derived verbs involving nouns and adjectives.

\subsection{The corpus}

The corpus used to carry out the present study is the Late Modern Spoken English-Old Bailey Corpus (LModE-OBC), a corpus collected by using the Procedings of the Old Bailey (available online at http//: www.oldbaileyonline.org), an important source of spoken language from past time (Huber 2007). The corpus covers a period of 100 years, from 1750 to 1850 , and it provides transcriptions of speech-based texts (Biber et al. 1998: 252; Culpeper and Kytö 2010: Ch.1) usually considered of great value for those interested in the development of English in a period predating the technology of audio recordings.

The selected texts belong to the legal genre, and specifically to the "legal-lay discourse" subgenre (Heffer 2005: 3; Williams 2013: 353) that involves interaction between legal professionals and lay people during trials in courtrooms. Despite the texts being characterised by the specific features of the legal genre, they represent an invaluable source of spontaneous speech (Biber 1988: 69) from past time, the speech-based texts that mostly bear resemblance to the spoken language.

All the selected texts contain direct speech dating back to the years 17501850 and are similar in length. The LModE-OBC consists of five subcorpora of 200,000 words each, and the whole corpus reaches a total of about $1,008,000$ words. 
Table 1: The LModE-OBC corpus architecture

\begin{tabular}{|l|l|l|l|}
\hline Subc-1 & $\begin{array}{l}1750-1759 \\
1760-1769\end{array}$ & \\
\hline Subc-2 & $\begin{array}{l}\text { 200,000 tokens } \\
\text { per } \\
\text { subcorpus }\end{array}$ & \multirow{2}{*}{$1,008,234$ tokens } \\
\cline { 1 - 2 } Subc-3 & $1780-1789$ & & \\
& $1790-1799$ & & \\
Subc-4 & $1800-1809$ & & \\
& $1820-1829$ & & \\
\hline Subc-5 & $1830-1839$ & & \\
& $1940-1849$ & & \\
\hline
\end{tabular}

The corpus has been automatically parsed by using VISL (Visual Interactive Syntax Learning), an interface which has been developed at the Southern Denmark University, covering 14 different languages (Bick 2001), that provides many tools, useful for parsing and POS tagging.

In addition to the LModE-OBC, to compare the findings with other texts dating back to the 18 th century, the ARCHER corpus ${ }^{2}$ was taken into consideration, and the whole section containing legal texts dating 1750-1850 was selected. As for the reference to PDE, instead, the materials used belong to the Phrases in English interface (PIE), ${ }^{3}$ which allows us to search through a selection of spoken legal presentations and debates contained in the British National Corpus (BNC) and, in addition, the Oxford English dictionary (OED).

In the present research, quantitative analysis makes use of Raw frequency $(R f)$, Normalized frequency $(N f)$ (base of normalization 10,000 words), percentage and percentage points.

\subsection{Method}

This study is configured as a corpus-based investigation which involves both quantitative analysis and qualitative interpretation in the description of language usage. Quantitative analytical techniques and qualitative statements represent the essential steps in language analysis because, according to Biber et al. (1998: 8-9), "statistical procedures are important for investigating complex association patterns" but, at the same time, a qualitative functional interpretation is essential for the "explanation, exemplification" (Biber et al. 1998: 8-9) of these patterns. 


\subsubsection{Procedure}

After the compilation and annotation of the LModE-OBC corpus with the VISL interface, I selected the linguistic features to analyse and I started the process of data retrieval by using the ConcApp Concordancer, which allowed me to search for a single word and a POS tag in all the texts under investigation.

As for VISL, it is an interface which is based on the Constraint Grammar (CG) methodology that contains many linguistic tools, like parsing and POS tagging. Its central principle is that it is focused on "surface structure (expressed as either dependency relations or syntactic tree structure) and the form function dichotomy” (Bick 2001: 2). The parser adds a tag with upper case letters for each word token followed by "the @-Symbol to introduce function tags, and arrow heads $(>,<)$ for head oriented dependency markers" (Bick 2001: 2). In addition, VISL provides lemmatization, inflection and shows the dependency links within a sentence. Table 2 shows a sample text taken from the annotated version of the LModE-OBC:

Table 2: Sample texts taken from the annotated version of the LModE-OBC

\begin{tabular}{|c|c|c|c|}
\hline POS & $\begin{array}{l}\text { Functional } \\
\text { categories }\end{array}$ & Definition & Examples \\
\hline $\mathrm{ADV}$ & (a)ADVL & $\begin{array}{l}\text { Adjunct [free] } \\
\text { adverbial }\end{array}$ & $\begin{array}{l}\text { I [I] PERS 1S NOM @SUBJ }>\text { drove } \\
\text { [drive] }<\text { mv }>\text { V IMPF @FS-STA on } \\
\text { [on] ADV @ }<\text { ADVL to [to] PRP @A }< \\
\text { the [the] ART S/P @ }>\text { N sign [sign] N S } \\
\text { NOM @P }<\text { of [of] PRP @N }<\text { the } \\
\text { [the] ART S/P @ }>\text { N Cheshire Cheese } \\
\text { [Cheshire=Cheese] N S NOM @P }<\end{array}$ \\
\hline $\mathrm{ADV}$ & @MV & $\begin{array}{l}\text { Main- verb } \\
\text { attached particle }\end{array}$ & $\begin{array}{l}\text { [I] PERS 1S NOM @SUBJ }>\text { got } \\
\text { [get] }<\text { mv }>\text { V IMPF @FS-STA up } \\
\text { [up] ADV@MV }<\text {, [,] PU @PU and } \\
\text { [and] KC @CO put } \\
\text { [put] <mv }>\text { V IMPF @FS-STA on } \\
\text { [on] ADV@MV }<\text { my [I] PERS 1S } \\
\text { GEN@ }>\text { N cloathes [cloathe] N P } \\
\text { NOM@ }<\text { ACC }\end{array}$ \\
\hline PRP & @ADVL & $\begin{array}{c}\text { Adjunct [free] } \\
\text { adverbial }\end{array}$ & $\begin{array}{l}\text { He [he] PERS MASC 3S NOM @SUBJ }>\text { left } \\
\text { [leave] }<\text { mv }>\text { V IMPF @FS-STA me } \\
\text { [I] PERS 1S ACC @ }<\text { ACC , [,] PU @PU to } \\
\text { [to] INFM @INFM go } \\
\text { [go] }<\text { mv }>\text { V INF @ICL- }<\text { ADVL on } \\
\text { [on] PRP @ }<\text { ADVL this [this] INDP } \\
\text { S @P }<\text { errands [errand] N P NOM @ }<\text { ACC }\end{array}$ \\
\hline
\end{tabular}


The extraction of syntactic constituents was carried out on the annotated version of the corpus.

Specifically, the tag selected to retrieve the data was V (verb) when followed by both ADV (adverb) and PRP (preposition). Considering that the particles in PVs are often categorized under the tags ADV with @MV > function, but sometimes also as ADV or PRP functionally behaving as adverbial, @ ADVL, a manual analysis has complemented the automatic analysis, in order to reduce inaccuracy. The tags and the functional categories which have been used in this research are represented in Table 3:

Table 3: Some VISL tags considered useful for the present study

\begin{tabular}{|l|l|l|}
\hline POS & Functional categories & Definition \\
\hline ADV & $@$ ADVL & Adjunct [free] adverbial \\
\hline ADV & $@ \mathrm{MV}<$ & Main-verb attached particle \\
\hline PRP & $@$ ADVL & Adjunct [free] adverbial \\
\hline
\end{tabular}

\section{Discussion and results}

Before discussing the mechanisms that influenced the emergence of PVs during the LModE period, some considerations on their distributional properties may be appropriate in order to understand the behaviour that generally characterised $\mathrm{PVs}$ in the period under investigation.

First, it should be noted that PVs are affected by relative stability over time. Looking at their frequency, as represented in Figure 1, in fact, it is possible to note that there is a slight increase in the 1770s followed by a drop in the 1790s. The same tendency can be found with reference to the following decades, the $1810 \mathrm{~s}$ and the $1830 \mathrm{~s}$, which are characterised by a sort of systematic trend marked by a slight variation in the frequency of use: ${ }^{4}$ 


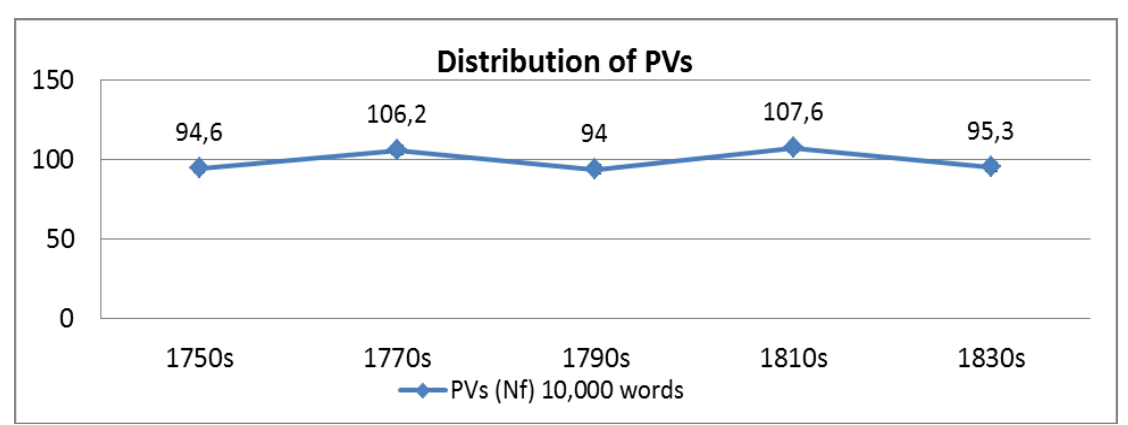

Figure 1: Distribution of PVs in the LModE-OBC

The lack of significant variation implies that the use of PVs is a well established feature of the LModE syntax in the century under investigation, and that they went through a process of consolidation in use and conventionalization in meaning. As a consequence, the fact that the frequency is attested to the same level within the decades may be seen as the outcome of the process of change that gave rise to PVs during the EME period (Denison 1981), but at the same time, a stability that may involve new processes of linguistic innovation and change especially in the semantic features. In fact, it is reasonable to consider this systematic trend as the input to the emergence of new meanings and new communicative functions. It is generally said that, during the LModE period, language was strongly orientated towards simplicity and formality (Crystal 2003 [1998]: 78-79), and this tendency may probably have limited the use of PVs in those years. In fact, PVs in general are often considered colloquial (Biber et al. 1999: 409) and related to an incorrect use of language, and for this reason, they were among the syntactic structures that were worth limiting when being used in formal contexts, such as in courtrooms. However, this does not mean that PVs were not affected by any kind of change. On the contrary, many changes occurred on both the lexical and the semantic levels. Table 4 shows the quantitative findings concerning the use of PVs in the LModE-OBC: 
Table 4: Distribution of PVs in the LModE-OBC

\begin{tabular}{|l|l|l|}
\hline Decade & PVs \% & Difference (Percentage points) \\
\hline $1750 \mathrm{~s}$ & 4.9 & \\
\hline $1770 \mathrm{~s}$ & 5.5 & +0.6 \\
\hline $1790 \mathrm{~s}$ & 5.2 & -0.3 \\
\hline $1810 \mathrm{~s}$ & 5.6 & +0.4 \\
\hline $1830 \mathrm{~s}$ & 4.7 & -0.9 \\
\hline
\end{tabular}

As Table 4 shows, in the first decades, from the 1750 s to the 1770 s, there is an increase of 0.6 in terms of percentage points followed by a decrease of 0.3 in the third decade. A slight increase followed by a much more significant decline up to 0.9 characterised the $1830 \mathrm{~s}$. This puts emphasis on the fact that PVs, far from being a stable group, displayed a kind of variation that allows us to claim for the existence of processes of change still operating and influencing their occurrence. On these assumptions, it becomes necessary to explain the factors and mechanisms that affected their frequency and use during the LModE period.

As stated above, the emergence of new PVs may be strictly connected with the process of analogy and direct formation. The analysis conducted on the LModE-OBC reveals that this is the kind of process that, during the LModE period, gave rise to many verbs, such as to pass by, to deliver back, to count out, to pay down, to quote some. More specifically, looking at the data, a verb that makes a case for this perspective, is the most frequently used verb conveying the meaning of 'to cause to return' (OED), to bring back, that gradually promoted the emergence of different PVs characterised by the same particle back, but with a different basis, in each case a basis conveying a meaning similar to the verb to bring.

For example, as represented in (1), the verb to bring back was used as a transitive PV, and it gradually promoted the establishment of different forms through analogical direct formation, as in the case of to deliver back, as in (2), and to take back, as in (3), that first appeared in 1770 and 1790 respectively:

(1) The hat is a very coarse hat; he sent it out once when he wanted money to pledge for a shilling; the pawnbroker would not lend a shilling upon it, and it was brought back; I believe the wig to be the same, I am positive the hat is. (1770s) 
(2) Yes, I delivered up the property, that is, I was the loser of the money, when Johnson told me the horse was advertized, and I was present when Johnson delivered back the horse to Houseman. (1770s)

(3) So that if any solder was taken back to Mess. Oakes and Brown's, the only omission was their not being acquainted with your course? - A. They ought to have called us to see it weighed. (1790s)

In fact, the verbs to take and to deliver, despite not being literal, all convey the meaning of 'to take someone or something from one place and have them with you when you arrive somewhere else' (MacmillanOnline) or more generally 'to get something for someone and give it to them' (MacmillanOnline). In this perspective, the additional particle puts emphasis on the action expressed by the verb and conveys the aspectual meaning of goal and purpose which is hidden in the base verb itself. In this regard, it should be noted that the particle back, as reported in the OED, is usually used with the general meaning of 'in a position to the rear, or away from the front', a meaning first attested c1300. Furthermore, this specific and well established connotation allows the particle, when used in complex verbs, to add some extra semantic meanings to the formative, contributing in this way to the lexicalization ${ }^{5}$ of the whole combination.

In the case of to bring back, for example, as reported in the OED, this verb was first used in the year 1662, as in (4), but it was only from the 19th century that it started to become established in use and meaning, as in (5) and (6), and thus also to show new combinatory properties:

(4) Yet didst thou..at length by a wonderful providence bring him back. (OED 1662 Bk. Com. Prayer, Chas. Martyr)

(5) I brought him back secretly into the city. (OED 1839 E. W. LANE tr. Thousand and One Nights I. 395)

(6) I trust the country air will bring back her strength. (OED 1861 EARL Stanhope Lfe W. Pitt I. i. 42)

In this regard, the ability to select different base verbs to combine with gave rise to other lexicalized forms such as to deliver back, to take back, in both cases first used as simple verbs that then acquired a particle making the action expressed by the verb characterised explicitly by a directional path, as in (7) and (8):

(7) I was present when Johnson delivered back the horse to Houseman, he took the horse home with him; I was the Rotation-office six or seven 
days after, I cannot tell the day; Justice Staples granted me a warrant to take the party if I found him, which I did not. (1770s)

(8) I took him back - he tried to get from us. It is worth $18 \mathrm{~d}$. per yard; there are forty-five yards. The shop is part of the dwelling-house; we both live there. (1810s)

Looking at these examples, it is evident that the verb to bring back has attracted other verbs and stimulated the use of the additional particle to the formatives which were similar in meaning. In this sense, this behaviour can be seen as the starting point of an analogical process, considered in terms of "generalization or optimization of a rule from a relatively limited domain to a far broader one" (Hopper and Traugott 2003 [1993]: 64). What emerges is that this kind of change, rather than involving grammaticalization in a narrow sense and reanalysis, operates on linguistic items modifying the external surface and, in the majority of cases, leaving unchanged some elements within the syntactic structure of the clause. In fact, in the examples discussed so far, the particle back and the whole syntactic structure $\mathrm{V}+$ Particle remains the same, the only change being the base verb that the particle is able to combine with. Thus, it can be assumed that the frequent use of to bring back has favoured the combination of the particle following different base verbs that were able to convey similar meanings, as in the case of to take and to deliver. Analogy, in fact, enables an existent form to behave as a catalyst for change contributing to the extension of a specific pattern in different linguistic contexts. This means that there would not be any kind of decategorialization or syntactic rebracketing. Instead, the formation of these new verbs was due to "the attraction of extant forms to already existing constructions" (Hopper and Traugott 2003 [1993]: 64). In this regard, the syntactic bracketing of to take back and to bring back is the same, and the additional particle does not change the basic structure of the preceding base verb; in this case to take continues to be transitive and followed by a direct object.

To take back-- [[to take back] something] to bring back --[to bring back] something]

To take ----- [[to take] something]

In fact, when a particle acquires "combinatory meanings" (Denison 1981: 163165 ) it is also able to be involved in direct formation and, in addition, it may give rise to analogical generalization. In this regard, the particle that is charac- 
terised by a high degree in terms of productivity also possesses a significant force on the paradigmatic level (Denison 1981: 164).

Thus, in the case of the particle back, it started to be used following other formatives in addition to the well established use with other verbs, like to get back, to give back, to bring back, all with the meaning of 'to give/bring something to the person who already owns it' (Macmillan). If some instances, like to bring back (9), to give back (10) and to get back (11) are taken into consideration, it should be noted that they have many similarities to the other derived forms that, once established, are also able to expand their meanings and to acquire additional contexts of use:

(9) I lost two pair of silk stockings, with my private mark upon them. I saw them about a quarter of an hour before she was brought back. (1770s)

(10) I told them that was the man and pointed to the prisoner; one went up to him, upon which the prisoner held a bayonet to his breast to keep him off and he was obliged to give back. (1770s)

(11) "Captain, you are anxious to get back your ring? it is in pledge at so and so "I said nothing to him before he said that my solicitor was with me I went by the Lord Mayor's permission. (1830s)

These verbs are in fact potentially involved in language change due to the acquired stability that they perform, an essential element to promote direct formation and analogical generalization. Looking at the occurrences of these verbs in the ARCHER corpus, in fact, they are similar to the instances found in the LModE-OBC, as in (12), but there are also different combinations characterised by the same features, as in (13):

(12) The express judgment is, "that he shall be taken back to the place from whence he came, and from thence to the place of execution. (ARCHER 1784doan 14a)

(13) The premium cannot be recovered back on account of the want interest, because the question of interest has nothing to do with. (ARCHER 1811 cous $15 b$ )

However, the direct formation of new patterns and the establishment of new items is only the most relevant change in lexical terms, because there is also evidence for an extension in meaning of the new combinations and a semantic shift 
to different contexts of use. This kind of change, for example, affected the verb to take back as represented in (14):

(14) I laid hold of them both and asked them where they were going with the barrel? They asked what it was to me? I said they should soon know what business it was to me. I called to some of the neighbours, as I was known there. They did not resist; I took them back to the shop and left two people in care of the arrel. (1770s)

The verb to take back, in fact, in addition to its literal use, acquired also the meaning of 'to accept someone again after they have left a relationship' (Macmillan), showing an innovative connotation that is also attested from the year 1799 onwards by the OED, as in (15), and since then, it became established in use and it is still frequent in PDE, as represented in (16). In this regard, there are no occurrences of this verb in the PIE legal texts, but this verb is reported in another genre, that is spontaneous spoken language, a fact which confirms that the lack of instances is to be treated as connected with the speakers' choice rather than with its existence:

(15) Holmes was with him for 15 or 16 months as an apprentice... He had no doubt of his honesty, and would take him back if acquitted of this charge. (OED 1799 Edinburgh Advertiser 10 Dec. 382/3)

(16) I knew I remember as clear as day, standing talking to Penny and I was calling their plumber, I'll always remember that and er I was quite took back and Penny said ooh she's been very good to me Yeah. (PIE KCP)

Similarly, the emergence of the verb to count out, first attested in the year 1830 in the LModE-OBC, can be seen as the outcome of a process of direct formation and a deriving form of other well established verbs like to pick out. This verb probably emerged by analogy through changes in the "paradigmatic organization, change in surface collocations, and in patterns of use" (Hopper and Traugott 2003 [1993]: 68) and, in addition, it can presumably be linked to the analogical generalization of the particle out in other contexts of use and in combination with different bases. More specifically, to pick out is a verb that conveys the meaning of 'to recognize someone or something from a group' (Macmillan), as in (17), and as a synonym of 'to select from a group with care or deliberation' (OED), as shown in (18):

(17) Hodgson picked out the prisoner directly; Hodgson had seen the pistols and the cutlasses before we went to the Mitre; his shop was in the way 
to the Mitre: he observed there was a notch in the stock of the pistol. (1790s)

(18) Dolphin picked out two of the largest screws, and put them into his pocket - we went to the Britannia public-house, in Golden-lane - Marr was with us. (1810s)

The fact that this is a well established use is confirmed by the OED, which reports some examples of it as far back as 1539, as in (19), and also some instances dating back to the LModE period, as in (20):

(19) Whan he had picked out ten thousand of the most valyant men of his hoost. (OED 1539 R. Morison tr. Frontinus Strategemes and Policies Warre I. sig. Aiiii)

(20) She has picked out such an ugly little devil, that strangers might imagine my wife was vulgar enough to be jealous of me. (OED 1810 Mrs. S. GREEN Romance Readers and Romance Writers I. 171)

These considerations should suggest that to pick out behaved as a model that other different simple lexical verbs followed, and that it was able to promote via analogy the use of the additional particle with other formatives, to provide the base verb itself with the meaning of 'to select' among different parts.

In this regard, a verb that can be considered as a representative case for direct formation through analogy is to count out, which first occurs in the $1830 \mathrm{~s}$ as a hapax legomena, as in example (21):

(21) I am now living with my mother and father Hallan got this lodging for me he is eighteen years old, I believe I am seventeen next April, and I believe Hughes is seventeen there was only one bed in the room Hughes used to sleep on a chair they knew I could see them while they were counting the things out. (1830s)

The fact that it is only used in one single sentence is not indicative of its own irrelevance in linguistic terms because, on the contrary, it is to be seen as the starting point of an ongoing process of change that got it established over time. This assumption is also confirmed by the OED, which outlines the origin and the use of this verb reporting that it first appeared in the year 1833 conveying the meaning of 'to count and give out or take out (from a stock)', as in (22):

(22) If no counting out of the House took place, the House might resume at 5. (OED 1833 [implied in: Ann. Reg. 34]) 
It is worth noting that there are no occurrences of this verb in the PIE legal texts, and more importantly, that it can only be found in the written texts, belonging to the newspaper section, as reported in (23). Of course, this could suggest that to count out has acquired a specialised use as a formal verb and is, thus, not very frequently used in spoken language:

(23) Detached garage PRICE: $£ 75,500$ Maths tests counted out MORE than half a million children have been spared three hours of national curriculum maths tests today. (PIE K3X)

In this regard, the verb to count out is to some extent similar to the verb to count, and this would mean that the only function that the particle performs is to provide the base verb with a specific semantic force. It is possible to hypothesise that the introduction of innovative ways to express the same concept to reach a high level of expressiveness is connected with both the necessity of enrichment in the informative contents and the functional pragmatic reasons orienting the discourse utterances (Heffer 2005: 36).

A more complex issue, in addition to what has been discussed so far, is the emergence of antonymous forms through analogy, as in the case of the pairs $u p /$ down, in/out and on/off. As Denison (1981: 165) claims, the use of the verb containing one particle within the pair can promote the rise of the corresponding alternative form, and he reports to switch on /to switch off as an example. However, the particle does not convey an antonymous meaning in all the cases, and, on the contrary, there are also instances where the particles can be considered in some contexts as alternative choices (Live 1965: 436). A representative example of the latter case is the pair to break up /to break down, two verbs that are diachronically connected and, thus, very similar in use. The first element to be noted is that they do not possess contrasting meanings, a fact confirming that they are not properly 'antonymous' in a strict sense but equivalent and different variants to express the same concept. In this regard, the OED reports that to break down and to break up have the meaning of 'to demolish, destroy' and 'to break into many parts' respectively and, thus, it can consequently be assumed that they may be used interchangeably but with a slight change in meaning, as in (24) and (25):

(24) I did not see Driscoll's windows smashed, and his shutters broken down when I came back from the hospital I saw they had been smashed I do not know who did it after Murphy was knocked down several women came round him and jumped on him I was not there the night before. (1830s) 
(25) It struck me that it was about the middle of May the firm was broken up, because I should have gone on the first Monday in June for the remainder of the bill, but I must be wrong this invoice is dated the $31 \mathrm{st}$ of August it must have been in September they were broken up it was about quarter-day. (1830s)

In these two examples, both the verb to break down and to break up convey the meaning of 'to remove, destroy' and possess the same syntactic and semantic features. From a diachronic perspective, looking at the data contained in the LModE-OBC, it can be hypothesised that the verb to break up, by analogy, modelled the emergence of the corresponding alternative verb to break down with a closer meaning. In fact, there are no instances of this verb conveying the meaning of 'to break into small pieces' (OED) before the 1830s, and this absence proves its connection with another verb, to break up, which was well established with this meaning at that time. In fact, considering that to break up conveys, in the majority of cases, this last meaning, as in (26), it is possible to suppose that its frequent use has given rise to the same connotation also in the verb to break down, as in (27):

(26) We found that on the table; here is a piece that appears to be an old mourning ring broke up (producing two pieces of gold, about three or four inches long) the other may be to make a new ring. (1750s)

(27) I am a headborough. I examined the premises on the 12th of December, between eleven and twelve o'clock in the morning - the paling was broken down, and appeared as if somebody had climbed over: I found two hats just by there, and took them to the watch-house: Alderton claimed one of them. (1810s)

In this case, analogy occurred through the semantic-pragmatic extension of an existing form and it consequently spread to new contexts of use and gradually underwent institutionalization. A possible explanation lies in the analogical direct formation that led the verb to break down to acquire a new meaning similar to that of the other verb, as in (28), due to the generalization of the meaning among antonymous pairs. This hypothesis is in line with what is expressed by the OED that, since 1382, attests that the verb to break down has the more general meaning of 'to demolish, to destroy', as in (29), whereas the other connotation of 'to break into small piece' is only attested from 1859 onwards, as in (30): 
(28) If a Ship be broken up, or taken in Pieces...and afterwards..be rebuilt..she is now another, and not the same Ship. (OED $1752 \mathrm{~W}$. Beawes Lex Mercatoria Rediviva 52)

(29) I shal breke down his wal. (OED a1382 Bible Wycliffite, E.V.)

(30) With delicious light French roll broken down into it. (OED 1859 J. M. JEPHSON and L. ReEve Narr. Walking Tour Brittany iv)

Turning to the case of direct formation consequent on the shift of a word from one grammatical class to another, there are no instances of direct formation and rule generalization resulting in zero-derived forms in the LModE-OBC. This is probably due to a well established process in the previous stages of English and, thus, a process that does not promote the emergence of new forms during the 18 th century. In this regard, it is possible to confirm the occurrence of specific verbs that contain an adjective or a noun as the base verb, but they display a high degree of stability and their emergence can be found as far back as the 17th century. Among them, some significant occurrences found in the LModE-OBC include the verb to clear up that, as also confirmed by the OED, first appeared in 1594, as in (31), and, as it happens in PDE, it conveys the meaning of 'to make clear', as in (32):

(31) Cleare $v p$ faire Queene that cloudy countenance. (OED 1594 SHAKESPEARE Titus Andronicus I. i. 263)

(32) I asked him at what time; and he said, at nine o'clock, at his house in Bedfont-lane, that was all that passed on the Sunday; accordingly I went on the Wednesday to the prisoner's house, having first gone to Sir William Gibbons, a Magistrate, to clear up the point, that I might not be thought to buy stolen goods. (1790s)

Similarly, the verb to light up, despite not being very frequent, is attested since the $1790 \mathrm{~s}$, as in (33), and it is used with the meaning reported in the OED, that is 'to furnish or to fill with abundance of light; to illuminate in a special manner; to bring into prominence by means of light', as in (34):

(33) Had there been fire-arms used by idle people to induce the neighbours to light up? - A. Yes. (1790s)

(34) An huge Room lighted up with abundance of Candles. (OED $1711 \mathrm{~J}$. AdDison Spectator No. 50) 
These considerations confirm that analogy influenced the emergence of new PVs, but, it also influenced the loss of PVs and, in some contexts, favoured the emergence of the simple verb instead of the original complex one. This must be seen in terms of direct formation of simple verbs from PVs, a process that has great importance when talking about PVs, because the appearance of new simple verbs is the outcome of the analogical process affecting PVs. In such cases, the PVs consisting of V + Particle gradually underwent syntactic changes characterised by the ellipsis of the particle after a process of progressive bleaching and functional weakness. For instance, this is the case of to turn about. Some examples of to turn about, as in (35) and (36), can give some elucidations on the process discussed so far. The verb to turn about is an intransitive PV relatively frequent in 1750 - 1770 decades but that gradually disappeared from 1790 onwards:

(35) Then he turned about and clapped the bayonet to my breast and demanded my money. I said friend I have but very little money for you. (1770s)

(36) He and I followed her into Smithfield; he overtook her; she turned about directly, and said she had nothing of his; at which time I saw her drop it again behind her; Mr Thorn went and took it; then the prisoner was very much confused. (1750s)

Interestingly, there are no instances of this verb either in the ARCHER corpus or in PIE, a fact that confirms the gradual disappearance of this verb. All this can be placed in line with what is expressed in the OED, which does not report examples containing this verb until the year 1609 , with no other instances after this date, as in (37):

(37) Through al monethes, that succede one another as the yeare turneth about. (OED 1609 Bible I. Num. xxviii. 14)

\section{Concluding remarks}

From a diachronic perspective, the emergence of new PVs can be considered strictly linked to the process of direct formation and analogical generalization, resulting in PVs as they are known in PDE. In fact, when a particle acquires a 'combinatory meaning', it is also able to be involved in direct formation and it may give rise to analogical generalization (Denison 1981: 163-165).

Factors that appear to be the most relevant include: 
- the occurrence of an analogical process, considered in terms of "generalization or optimization of a rule from a relatively limited domain to a far broader one" (Hopper and Traugott 2003 [1993]: 64) that gave rise to new PVs;

- the semantic-pragmatic extension of existing forms and the emergence of antonymous pairs via analogy;

- the direct formation of simple verbs from PVs after syntactic changes characterised by the progressive bleaching and functional weakness of the particle via rule generalization.

The data contained in the LModE-OBC reveals that, by analogy, some verbs modelled the emergence of different PVs through direct formation and analogical generalization, as in the case of to bring back, which promoted other verbs such as to take back and to deliver back. On the contrary, other PVs started to behave as simple verbs due to the loss of the adverbial particle as a consequence of the generalization of syntactic patterns which were very frequent in other simple verbs, similar in meaning.

As for direct formation and rule generalization resulting in zero-derived forms, no occurrences can be found in the LModE-OBC, and this means that this is probably a process well established in the previous stages of English, and that does not promote the emergence of new forms in the 18th century.

Differently, in the case of antonymous forms (up/down, in/out and on/off), analogy worked through the semantic-pragmatic extension of existing forms and institutionalization due to the generalization of the meaning between antonymous pairs.

\section{Acknowledgements}

I would like to express my gratitude to my supervisor Professor Rita Calabrese for her support and encouragement.

\section{Notes}

1. Conventionalization is a term used as a synonym for institutionalization and refers to the process that allows "new forms innovated on the basis of word formation rules (...) to be conventionalized as part of the accepted vocabulary of a community" (Brinton and Traugott 2005: 45).

2. http://www.alc.manchester.ac.uk/subjects/lel/research/projects/archer/

3. http://www.phrasesinenglish.org 
4. I have reported the Normalized Frequency $(N F)$ because, in order to compensate any differences in length between the subcorpora, Raw Frequency $(R F)$ was normalized to a base of 10,000 words.

5. The term lexicalization refers to the diachronic process that gives rise to new lexical forms/items (Brinton and Traugott 2005: 96) also resulting from the fusion of words (Brinton and Traugott 2005: 47).

\section{References}

Biber, Douglas. 1988. Variation across speech and writing. Cambridge, UK: Cambridge University Press.

Biber, Douglas, Susan Conrad and Randi Reppen. 1998. Corpus linguistics. Investigating language structure and use (Cambridge Approaches to Linguistics). Cambridge, UK: Cambridge University Press.

Biber, Douglas, Stig Johansson, Geoffrey Leech, Susan Conrad and Edward Finegan. 1999. Longman grammar of spoken and written English. Harlow, UK: Pearson Education Limited.

Bick, Eckhard. 2001. The VISL System: Research and applicative aspects of ITbased learning. Proceedings of NoDaLiDa (Uppsala). http://www.stp.lingfil.uu.se/nodalida/2001/pdf/NODALIDA02/pdf (accessed 15 April 2014)

Bolinger, Dwight. 1971. The phrasal verb in English. Cambridge, MA: Harvad University Press.

Brinton, Laurel J. 1988. The development of English aspectual systems. Aspectualizers and post-verbal particles (Cambridge Studies in Linguistics 49). Cambridge, UK: Cambridge University Press.

Brinton, Laurel J. and Minoji Akimoto (eds.). 1999. Collocational and idiomatic aspects of composite predicates in the history of English (Studies in Language Companion series 47). Amsterdam \& Philadelphia: John Benjamins Publishing Co.

Brinton, Laurel J. and Elizabeth Closs Traugott. 2005. Lexicalization and language change (Research Surveys in Linguistics). Cambridge, UK: Cambridge University Press.

Campbell, Lyle. 2013 [1998]. Historical linguistics. An introduction, 3rd edn. Edinburgh: Edinburgh University Press.

Claridge, Claudia. 2000. Multi-word verbs in Early Modern English. A corpusbased study. Amsterdam \& Atlanta: Rodopi.

Crystal, David. 2003[1998]. The Cambridge encyclopedia of the English language, 2nd edn. Cambridge, UK: Cambridge University Press. 
Culpeper, Jonathan and Merja Kytö. 2010. Early Modern English dialogues: Spoken interaction as writing (Studies in English Language). Cambridge \& New York: Cambridge University Press.

Denison, David. 1981. Aspects of the history of English group-verbs: With particular attention to the syntax of the Ormulum. Oxford: University of Oxford DPhil dissertation. https://www.escholar.manchester.ac.uk/uk-acman-scw:74782. (accessed 8 January 2016.)

Denison, David. 1998. Syntax. In S. Romaine (ed.), The Cambridge history of the English language. Volume IV: 1776-1997, 92-329. Cambridge, UK: Cambridge University Press.

Fischer, Olga. 2007. Morphosyntactic change: Functional and formal perspectives (Oxford surveys in Syntax and Morphology). Oxford: Oxford University Press.

Fraser, Bruce. 1974. The verb-particle combination in English. Tokyo: Taishukan Publishing Company.

Heffer, Chris. 2005. The language of jury trial. A corpus-aided analysis of legallay discourse. New York: Palgrave Macmillan.

Hiltunen, Risto. 1999. Verbal phrases and phrasal verbs in Early Modern English. In L.J. Brinton and M. Akimoto (eds.). Collocational and idiomatic aspects of composite predicates in the history of English (Studies in Language Companion series 47), 133-165. Amsterdam \& Philadelphia: John Benjamins.

Hopper, Paul J. and Elizabeth Closs Traugott. 2003 [1993]. Grammaticalization (Cambridge Textbooks in Linguistics), 2nd edn. Cambridge, UK: Cambridge University Press.

Huber, Magnus. 2007. The Old Bailey Proceedings, 1674-1834: Evaluating and annotating a corpus of 18th- and 19th-century spoken English. In A. Meurman-Solin and A. Nurmi (eds.). Annotating variation and change (Studies in Variation, Contacts and Change in English 1). http://www.helsinki.fi/ varieng/journal/volumes/01/huber/. (accessed 16 January 2012.)

Kennedy, Arthur Garfield. 1920. The modern English verb-adverb combination (Stanford University Publications University Series, Language and Literature, Vol. 1, No. 1). Stanford: Stanford University Press.

Live, Anna H. 1965. The discontinuous verb in English. Word 21 (3). 428-451. http://www.tandfonline.com/doi/pdf/10.1080/0043795.1965.11435439. (accessed 29 August 2015.)

OED. Oxford English dictionary. http://www.oed.com. 
Macmillan dictionary (online). http://www.macmillandictionary.com

Macmillan phrasal verbs plus dictionary. 2005. Oxford: Macmillan Publishers.

Rodríguez-Puente, Paula. 2012. The development of non-compositional meanings in phrasal verbs. A corpus-based study. English Studies 93 (1). 71-90.

Thim, Stefan. 2012. Phrasal verbs. The English verb-particle construction and its history (Topics in English Linguistics 78). Berlin \& Boston: De Gruyter Mouton.

Traugott, Elizabeth Closs. 2011. Grammaticalization and mechanisms of change. In H. Narrog and B. Heine (eds.). The Oxford handbook of grammaticalization (Oxford Handbooks in Linguistics), 19-30. Oxford: Oxford University Press.

Traugott, Elisabeth Closs and Graeme Trousdale. 2010. Gradience, gradualness and grammaticalization: How do they intersect? In E. C. Traugott and G. Trousdale (eds.). Gradience, gradualness and grammaticalization (Typological Studies in Language 90), 19-44. Amsterdam \& Philadelphia: John Benjamins.

Wanner, Dieter. 2006. The power of analogy. An essay on historical linguistics. Berlin \& New York: Mouton de Gruyter.

Williams, Christopher. 2013. Changes in the verb phrase legislative language in English. In B. Aarts, J. Close, G. Leech and S. Wallis (eds.). The verb phrase in English. Investigating recent language change with corpora (Studies in English Language), 353-371. Cambridge, UK: Cambridge University Press.

\section{Relevant websites}

http://www.alc.manchester.ac.uk/subjects/lel/research/projects/archer/ http://www.phrasesinenglish.org http://www.oldbaileyonline.org http://www.macmillandictionary.com 